$\begin{array}{llll}\text { Al-Rafidain Engineering } & \text { Vol.16 } & \text { No.3 } & \text { Aug. } 2008\end{array}$

\title{
Relation Between Pre Straining Before Welding, Joint Design, And Microstructure In Welding Of (7020) Aluminium Alloy
}

\author{
* Shawnim R. Jalal \\ University of Salahadeen, College of engineering, Mechanical department - \\ Iraq-Erbil \\ *E-mail Shawnim100@yahoo.com
}

\begin{abstract}
Abstaract
In the utilization of aluminum alloys for structural applications, one difficulty to be overcome is the reduction of mechanical properties of welded joints as compared to the parent material, consequent upon the weaker strength of the welded metal (WM) and the distortion in the heat affected zone (HAZ) due to the welding thermal cycle. In the present investigation the tensile characteristics of joints welded plates of 7020 alloy under Arc welding at different pre strain before welding $(5,10,20,30 \%)$ and joint design (single and double $\mathrm{V}$ with angles equal to $70^{\circ}, 80^{\circ}, 90^{\circ}$ ) are investigated , and the subsequent microstructure evolution after welding is assessed which improve the properties. This paper show that the improvement in mechanical properties (Yield and Tensile strength) carried out with $20 \%$ pre strain at a single $\mathrm{V}$ with angle equal to $90^{\circ}$ compared with double $\mathrm{V}$ and reduced with increasing pre strain $(30 \%)$ due to phase transformation of $\eta$ to the stable microstructure $\eta$ (MgZn2). And changing joint design angles has little effect on mechanical properties improvement compared with joint design shape (single and double $\mathrm{V}$ ) .
\end{abstract}

Keywords: 7020 Aluminum alloy; pre strain ; Arc welding ; joint design

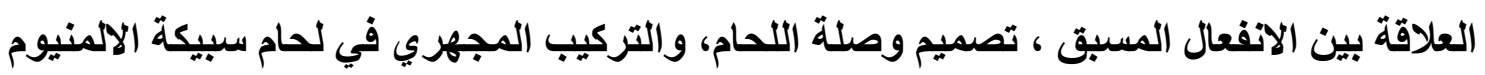




\section{شونم رشيد جلال \\ كلية الهندسة ـ قسم الميكانيك- جامعة صلاح الدين}

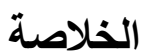

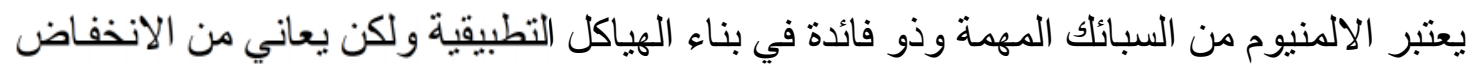

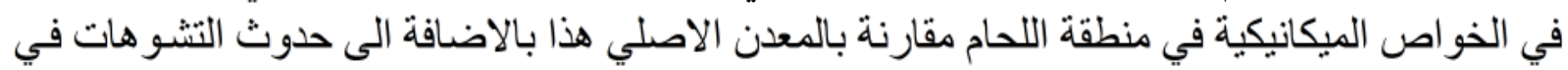

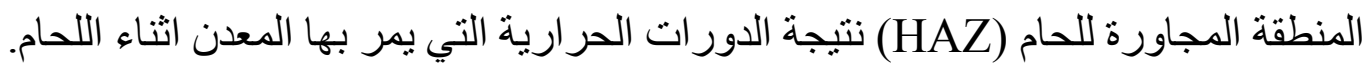

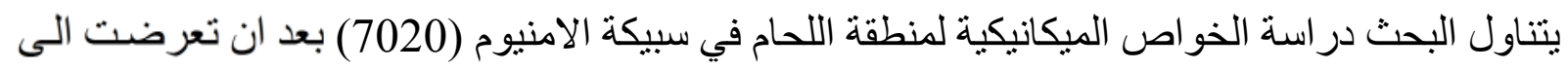

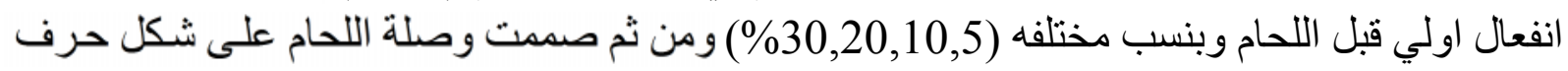

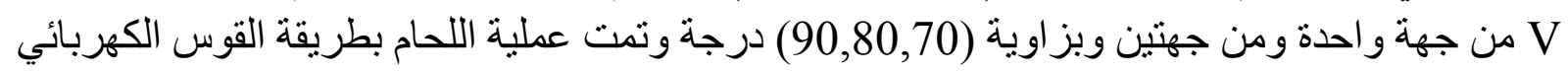

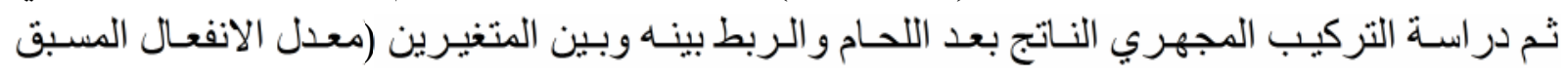

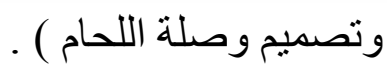

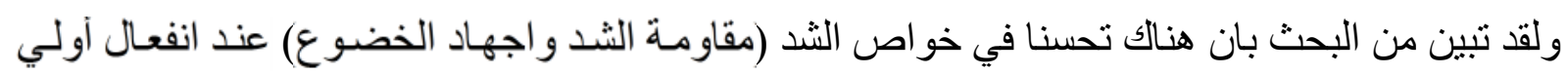

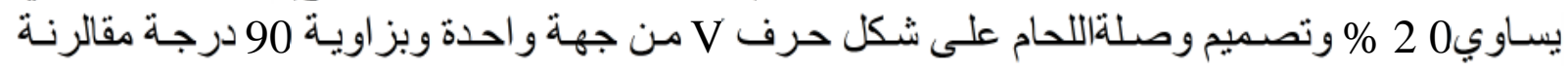

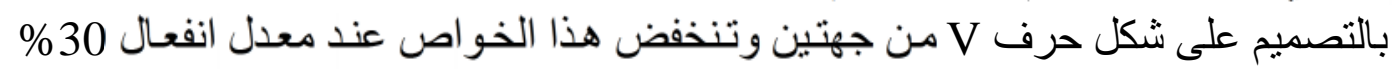

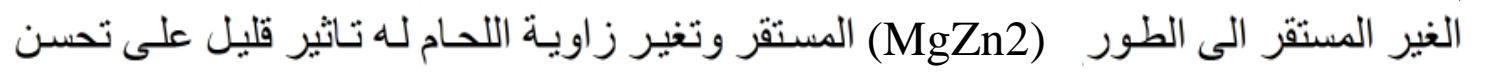

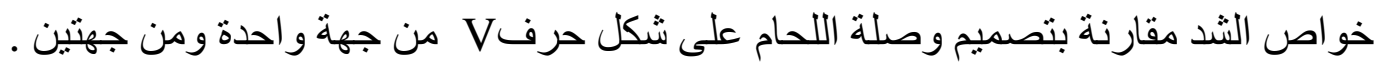

Received 21 Feb. 2007

Accepted 3 Sep. 2007

\section{Introduction:-}

Aluminum is high strength (7000) series based on $\mathrm{Al}-\mathrm{Zn}-\mathrm{Mg}$ system are widely used for structural application in aerospace, automotive industry, auto parts and bombers due to their high specific mechanical properties [1-2] .

But these alloys are not weldable which means it can not be fusion welded without experiencing a large amount of cracking during solidification in the weld due to copper presence in these alloys although one type of these alloys ( 7020 ) is generally middle strength and gives high strength of welded joints compared to all other weldable $\mathrm{Al}$ alloys [1-3-4 ] . 
These alloys differ from other weldable Al alloys in that they are age harden significantly at room Temp. Moreover the strength properties that are developed are relatively insensitive to rate of cooling from the high temperature, and they possess a wide temperature range for solution treatment, i.e. $350{ }^{\circ} \mathrm{C}$ and above, with the welding process itself serving this purpose [5] .

The 7000 series studied here are especially sensitive to welding because their microstructure is not stable with temperature ,these alloys have gained strength through a complex precipitation sequences including metastable phase (Guiner Preston zone)and $\dot{\eta}$ phase and stable particles (essentially the $\eta$ phases thus their modification during welding is a limited issue [2] .

Welded joints in $\mathrm{Al}$ unlike structural steel, tend to suffer serious weakening in the heat affected zone HAZ softening, and the strength can be nearly halved after welding so $\mathrm{Al}$ joints sometimes fail in the weld metal and sometimes in the HAZ depending on the combination of being used [1-6-7] .

In this investigation we studied the effect of pre strain ( dislocation forming or the relation between dislocation and microstructure ) before welding on some mechanical properties for $7020 \mathrm{Al}$ alloys by manual arc welding were no research has focused on it .

\section{Experimental procedures :}

The material used in this investigation was wrought $\mathrm{Al}$ alloy type (7020) having chemical composition of ( $\mathrm{Al}-4.5 \% \mathrm{Zn}-1.2 \% \mathrm{Mg}-0.05 \% \mathrm{Zr}-0.035 \% \mathrm{Si}-0.25$ $\% \mathrm{C} \mathrm{r}-0.33 \% \mathrm{Mn}-0.4 \% \mathrm{Fe}-0.2 \% \mathrm{Cu}$.

Specimen of dimension $(200 \times 25 \times 15) \mathrm{mm}$ were prepared from plates $(15 \mathrm{~mm})$ thickness which was at $\mathrm{T} 6$ condition (heating at $480{ }^{\circ} \mathrm{C}$ for $30 \mathrm{~min} .+$ water quenching $+6 \mathrm{hrs}$. at $100{ }^{\circ} \mathrm{C}+15 \mathrm{hrs}$. at $140{ }^{\circ} \mathrm{C}$ ) at peak condition when the mechanical properties were high .The specimen were subjected to $5,10,20$, $30 \%$ pre strain before welding by using compression machine then the joint configuration prepared by milling machine for all the weldments which consists of a single $\mathrm{V}$ (groove) and double $\mathrm{V}$ with angles equal to $70^{\circ}-80^{\circ} 90^{\circ}$ with a root hight ( c) of $2 \mathrm{~mm}$ in a single $\mathrm{V}$ and $3 \mathrm{~mm}$ in double $\mathrm{V}$ as shown in fig. 1 [4-8] . 


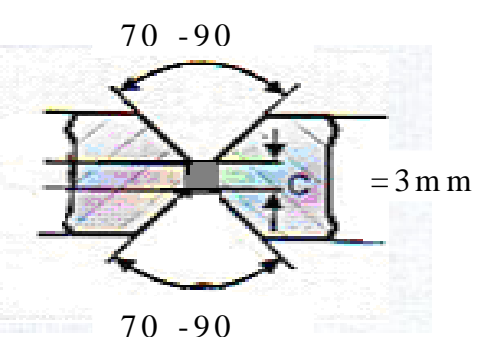

Double V design

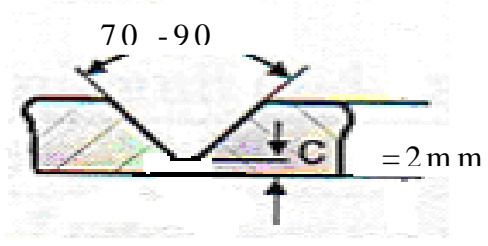

S ingle $\mathrm{V}$ design

Fig.1 Show the joint design (4-8)

Metal manual arc welding processes have been selected for this alloy with ( volts $=26 \mathrm{~V}$, current $=240 \mathrm{Amp}$, welding speed $=540 \mathrm{~mm} / \mathrm{min}$ ) which have been developed more recently than gas welding owing chiefly to the inherently unstable nature of arcs between $\mathrm{Al}$ electrodes. In the arc welding of $\mathrm{Al}$ there remains a tendency to unsoundness in the weld .[8]

Welding has been done with filler type (4043) and composition of the filler was (4.5-6\% Si , 0.8\% Fe ,0.3\% Cu , 0.05\% Mn , $0.05 \% \mathrm{Mg}, 0.1 \% \mathrm{Zn}, 0.2 \% \mathrm{Ti}$ and the $\mathrm{Al}$ is rest ).[4-9]

The tensile test specimens were machined from welded samples according to the ASTM A 370 standard with a gauge length of $(25 \mathrm{~mm})$ and $(6.25 \mathrm{~mm})$.[10]

The TERCOMT 3037 universal tensile and compression test machine used to get the results of yield, tensile strength and elongation with the strain rate of $0.036 \mathrm{~S}^{-1}$.

To investigate the metallurgical aspects (shapes and size ) of grains optical microscope used for some specimens after grinding, polishing, and etching then using tuker followed by keller reagent. [10]

\section{Result and discussion:}

The mechanical properties produced after welding are not very high therefore many previous researches tend to improve the properties by many methods such as heat treatment before and after welding, changing the welding parameter, process welding ......etc. But our research used strain before welding to 
improve the mechanical properties .We used the alloy in peak condition T6 before pre strain because the microstructure of this condition formed from $\dot{\eta}$ (The intermediate and unstable phases ) where the strength and hardness was high [11] .

The yield and tensile strength for above conditions before welding were 310 ,392 Mpa respectively but after welding the evolution reduced for all specimen subjected to pre strain in the two condition(single and double $\mathrm{V}$ design), in this context D.A.shelwatkar [3] observed that the softening in the welded metal is usually explained based on the coarsening of the metastable phase due to the temperature increases also the heat of welding acts as a local annealing operation reduced the strength of the weld [12] .

Figs. 2,3 show the reduction in mechanical strength after welding for single $\mathrm{V}$ design such as the reduction in yield strength reaches $54 \%$ (without strain ),53\% at low rate of pre strain (5\%),43\% at high pre strain $(20 \%)$ and increased after that to reach $57 \%$ at $30 \%$ pre strain .

It was suggested that as pre strain $\%$ precedes dislocation will tend to pile up at crystal boundaries and will be regions of increased potential energy due to the extra micro-stresses present there. For this reason the grain boundary areas become weak and failure will accelerated given low value of strength with little improvement in elongation fig.4 [13] .

In single $\mathrm{V}$ design we can observe that the heat input is low compared to the double $\mathrm{V}$ design so it is cooled fast and thus homogenous nucleation occur which promotes the formation of large number of nuclei but smaller in size. Microstructure No. 1,2.

This decrease in grain size subsequently increases the mechanical properties compared with double $\mathrm{V}$ design, it means the improvement in the yield and tensile strength related to the micro structural refinement.

Increasing single $\mathrm{V}$ design from $70^{\circ}$ to $90^{\circ}$ improves mechanical properties slightly because large angles means the volume of the filler was high and the mechanical properties for the filler was low compared with base metal but large angles means more pass welding, more heat input and more interaction between the filler and base metal which improve the mechanical properties. [14] 
Also the filler metal (A15Si) which is used causes an increase in mechanical properties of weld regions because it possesses a wide freezing range and during solidification the (A15Si) alloy contract is less than all or any of the other alloys so that the risk of cracking is likely to be lower[15-16] ,

The mechanical properties are lowered in double V design ( figs. 5-6 ) due to the increase in the heat input to the weld zone therefore the weld zone cools slowly which promotes the formation of few nuclei but large in size precipitates $\eta$ (MgZn2) over aged condition which occurred due to phase transformation $\dot{\eta}$ to $\eta$ microstructure No. 3-4 and this grain growth causes the reduction in mechanical properties . 


\begin{tabular}{llll} 
Al-Rafidain Engineering & Vol.16 & No.3 & Aug. \\
\hline
\end{tabular}

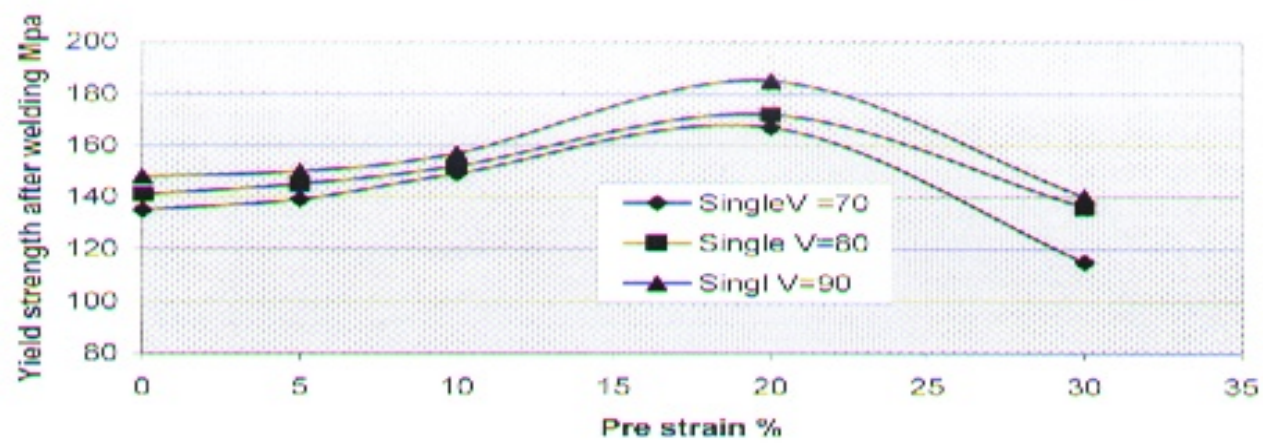

Fig. 2 the relation between pre strain and yield strength after welding for single $\mathrm{V}$ design

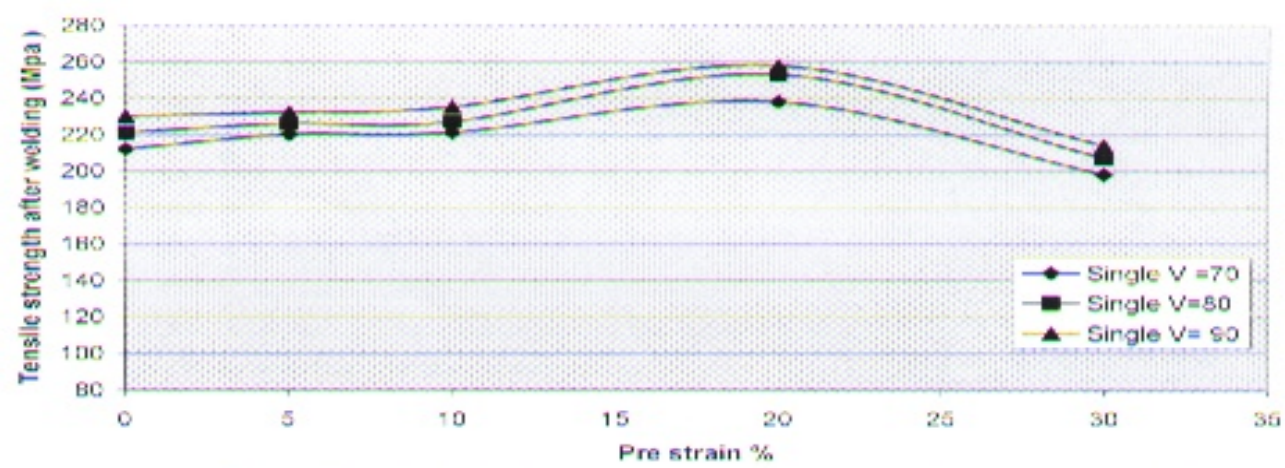

Fig. 3 the relation between pre strain and tensile strength after welding for single $V$ design

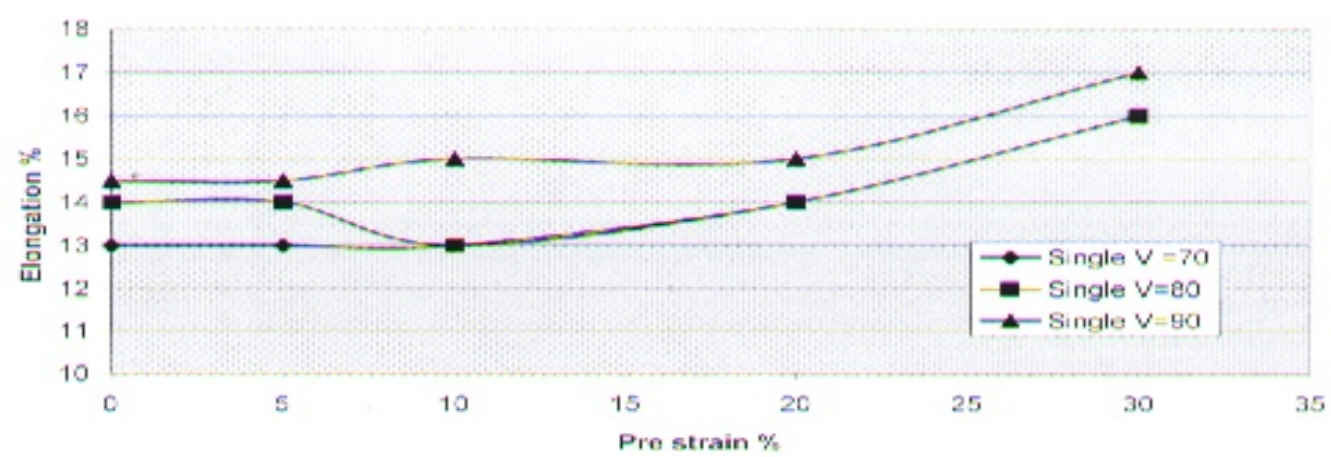

Fig 4 the relation between pre strain and elongation $\%$ after welding for single $V$ desin 


\section{$\begin{array}{llll}\text { Al-Rafidain Engineering } & \text { Vol.16 } & \text { No.3 } & \text { Aug. } 2008\end{array}$}

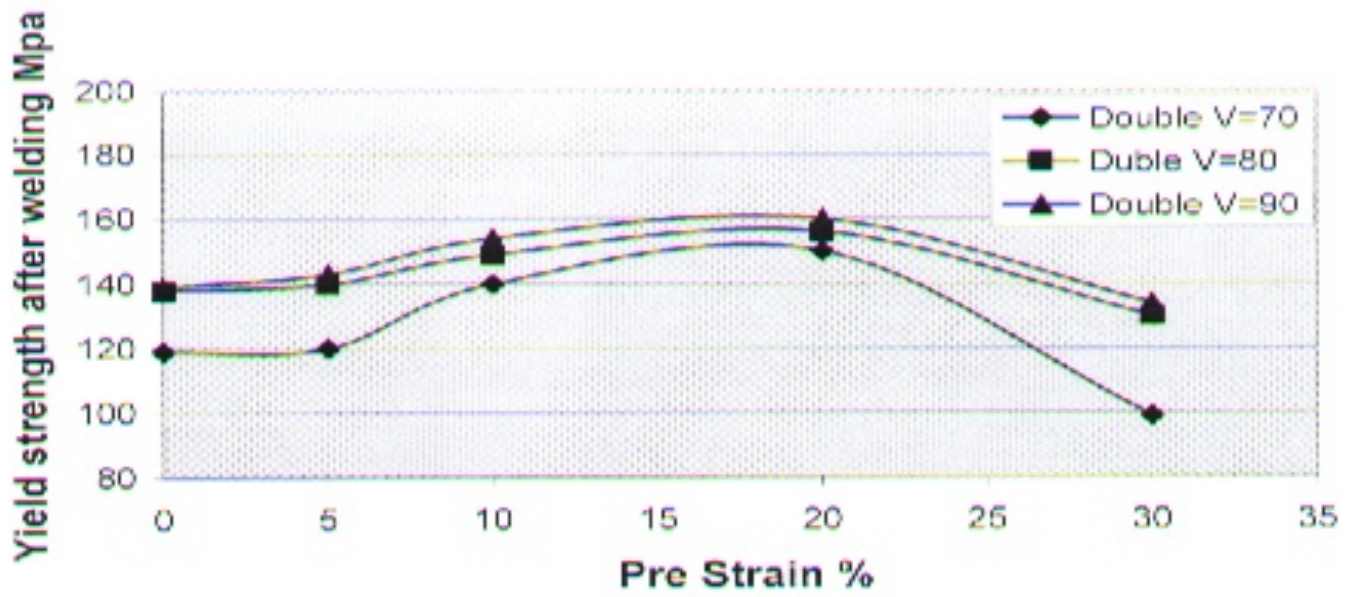

fig. 5 the relation between strain rate and yield strain after welding for double $V$ design

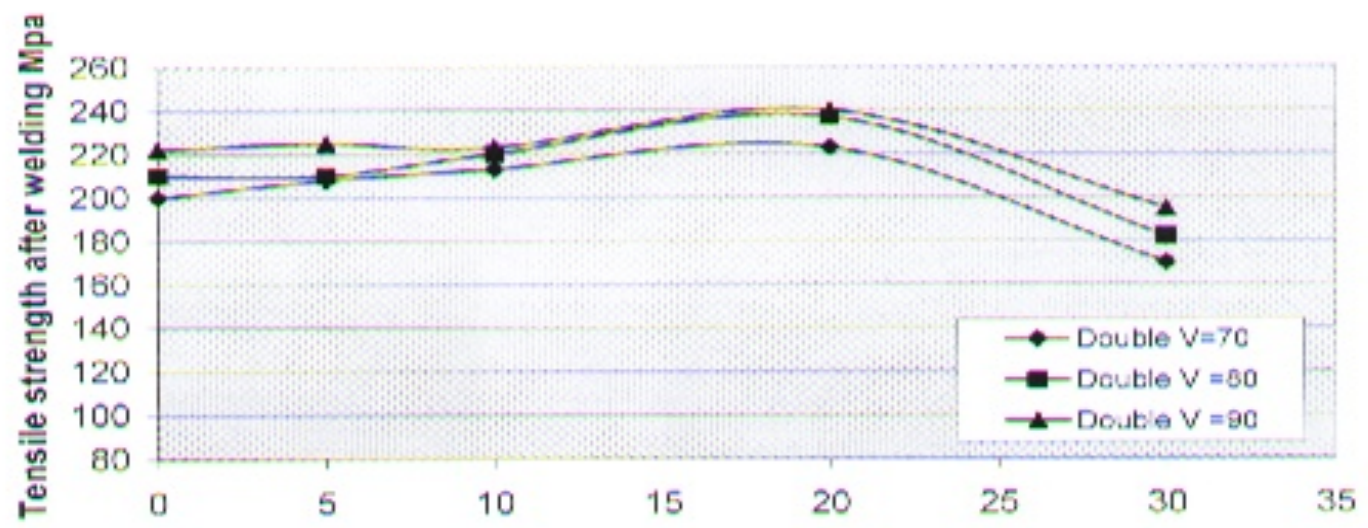

Pre strain \%

Fig .6 the relation between pre strain and tensile strength after welding for double $\vee$ design

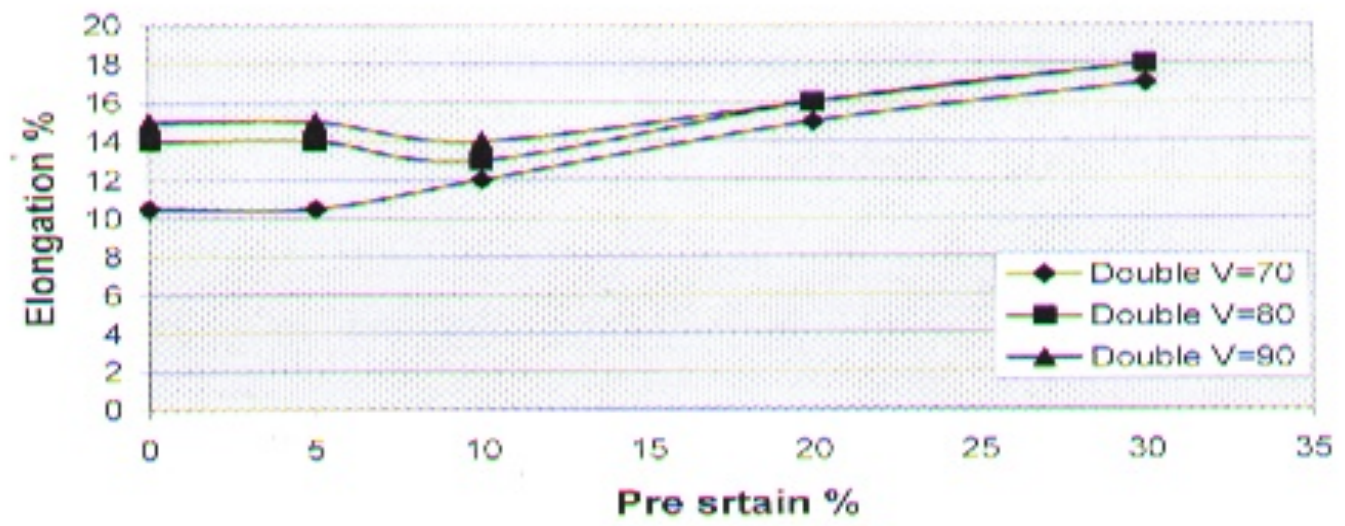

Fig. 7 the relation between strain rate and elongation after welding for double $V$ design 


$\begin{array}{llll}\text { Al-Rafidain Engineering } & \text { Vol.16 } & \text { No.3 } & \text { Aug. } 2008\end{array}$
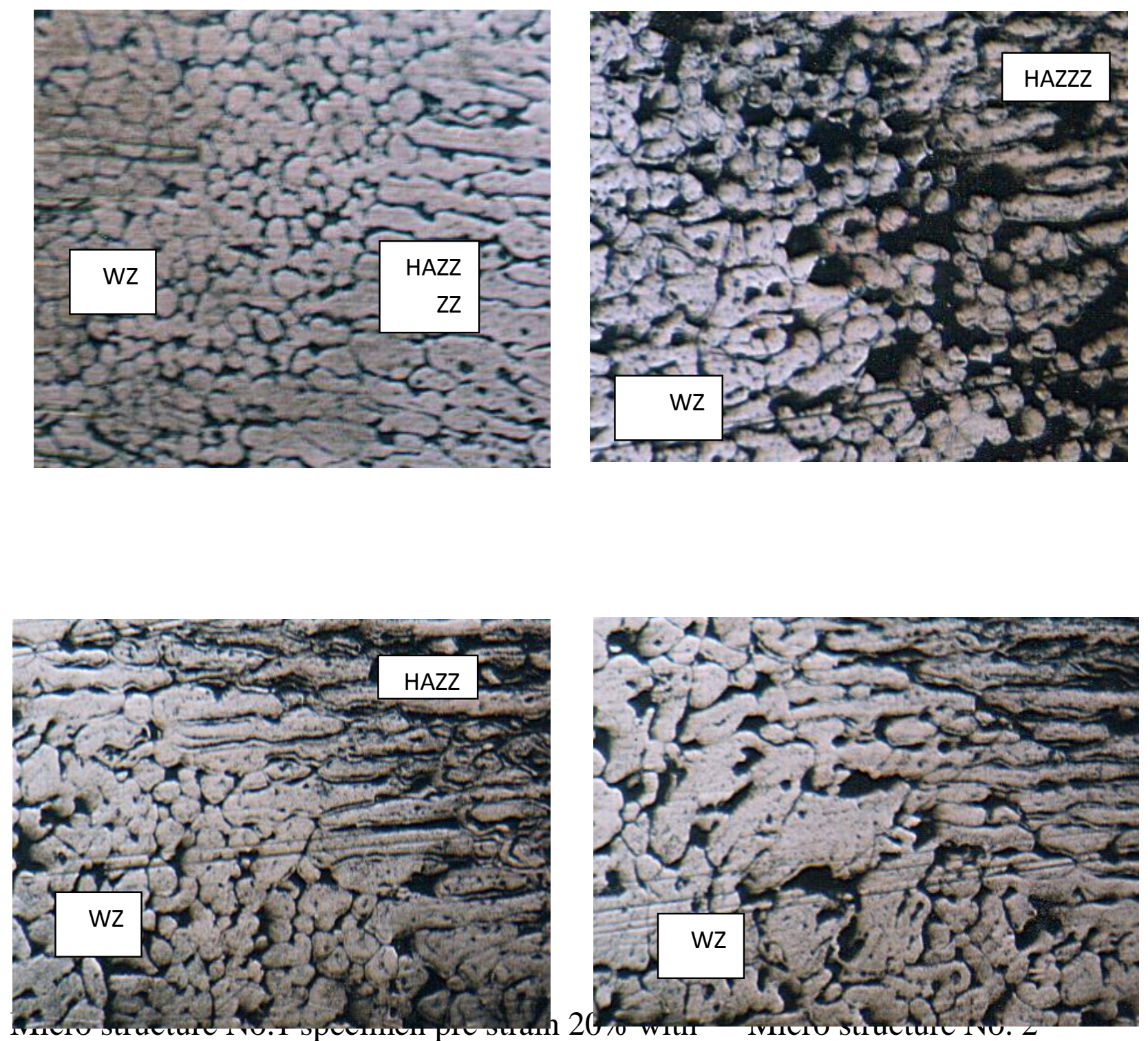
specimen pre stain $5 \%$

single $\mathrm{V}$ design long grains (HAZ) and equiaxed grain (HAZ) and

with single $\mathrm{V}$ design long 
grain weld zone.(300X)

equiaxed grain weld zone. $(300 \mathrm{X})$

Micro structure No.3 specimen pre strain 20\% with double $V$ design long grains (HAZ) and equiaxed grain weld zone.(300X)
Micro structure No.4 specimen pre strain 5\% with double $V$ design long grain (HAZ) and equiaxed grain weld zone.(300X)

Increasing heat input over aging occurs much more rapidly (double Vwith angles $=90^{\circ}$ ) and the meta stable equilibrium $\dot{\eta}$ does not persist, this is though to indicate that the $\eta$ phase is no longer able to survive so the yield and tensile strength were reduced rapidly with improving elongation fig. 7

In this context Dumont et al [17] studied the relationship between microstructure, strength , and elongation ,they found that elongation is confirmed to be minimum at peak strength and modified for over aged 
(MgZn2 ) microstructure, also they described the evolution of elongation as a function of microstructure parameters precipitates (coarse or fine )on grain boundaries and the value of yield strength .

It can be observed by visual inspection of the specimens that more welding heat may cause distortion and buckling of double $\mathrm{V}$ design compared with single $\mathrm{V}$ design. This is attributed to that the total heat input is greater and it is more diffuse, so during cooling the specimen distorted due to local stress, For these reasons proper joint design, edge preparation will counteract this tendency [ 8] .

Decomposition and precipitation due to heat in this alloy system has not yet been correctly solved even though several attempts has been made and in 7000 series alloys the effect of heterogeneous precipitation is more complex in contrast to other $\mathrm{Al}$ alloys [18] .

\section{Conclusions :-}

1-The combined strengthening effect of the precipitation from welding (heat input) and the high dislocation density (from pre strain \%) improved mechanical properties after welding .

2-The best result has been appeared to the samples having the geometrical shape $\left(90^{\circ}\right.$ single $\left.\mathrm{V}\right)$ design compared with double $\mathrm{V}$ design .

3-Mechanical properties improved until $20 \%$ pre strain and reduced after that at (30\% pre strain).

4-Joint design angles has little effect on mechanical properties improvement compared with joint design shape (single and double V) .

5-Interaction between the heat input ,microstructure, pre strain \%, and design of welding joint (shapes and angles ) is complex and more detailed studies are needed to better understand this phenomena . 


\section{References:-}

1- Dwight, j. b "Aluminum design and construction" E\& FN spon, 1999 pp.1-13 \&46-100.

2- M.Nicolas,A.Deschamps "precipitation microstructure and resulting properties of $\mathrm{Al}-\mathrm{Zn}-\mathrm{Mg}$ weld heat affected zones"Metallurgical and material transaction, vol.35A (5] (2004)pp.1437-1448)

3-D.A.Shelwatkar,G.MadhusudhanReddyandA.Gokhale"Gas tungsten Arc Welding studies on similar and dissimilar combinations of Al-ZnMg alloy RDE 40 and Al-Li alloy 1441 "Science and Technology of welding and joining, vol.7 ,no.6, 2002

4-Ulrich Krnger "Weldability" TALAT Lecture 4202, EAA, 1994, pp.312.

5-Polwer, I.J "Light Alloys Metallurgy of the Light Metals"Edward MOLD Metallurgy and material science (1989),pp18-145

6-Johannessen, Jan Inge F.,Hydro Al structures and Karmoy "Structural Materials FabricationTALAT2203 , EAA,1994, pp.19-40

7-Dobmeier, Jeffery $\mathrm{M}$ and Gomes,Peter $\mathrm{P}$ 'Analyticalandexperimental evaluation of an Al bridge deck panel" part 2 Service load performance, 1999, charlottesivlle, VA,Virginia , pp.11-18.

8- O.P.Khanna"ATextBook of welding technology"Dhanpat Rat LTD 2004 pp.411

9-Prof. ir. F.Soetens "Design of welded Al connections" Eindhoven university of Technology 2001

10- Annual book of ASTM standards ,part 2 Ferrous casting ,Ferro alloys ,(1982)pp.(225-226),pp.(309).

11-A. Deschamps.F. Livet,Y.Brechet "Influence of pre-deformation on aging in an Al-Zn-Mg alloy -1- microstructure evaloution and mechanical properties" Acta mater,Vol.47 (1999)pp.117-124.

12-Frank g .Armao "proper design of aluminum weldment "Metal forming magazine, April 2000, pp.35-36. 
13-Higgins,R.A "Engineering metallurgy , Applied physical metallurgy" Sixth Edition ,Edward Arnold , 1998 , pp.175.

14-Muafaq Mehdi Salih "Studying the effect of joint design at the welding process (MIG) on the mechanical properties of the aluminum alloy (7020-T6)" M. SC. Thesis, university of technology 2005 .

15-A.K. Mukho Padyay G.M.Reddy"Microstructure property relation ships in a high strength $\mathrm{Al}-\mathrm{Zn}-\mathrm{Mg}-\mathrm{cu}-\mathrm{Zr}$ alloy"Materials Forum ,vol.28,2004, pp.883-888,

16-Y,M.Zhang and S.B.Zhang "Welding Al alloy 6061 with the opposing dull torch GTAW process" wilding research (202-206) , June 1999.

17-D.Dumont,A. Deschamps, Y. Brechet,"On thr relation ship between microstructure strength and toughness in AA 7050Al alloy", materials science and Engineering, Aoo,(2003),pp.1-11.

18- A. Deschamps.,Y.Brechet "Influence of quench and heating rates on the aging response of an Al-Zn-Mg-Zr alloy" material science and Engineering, A251 (1998, PP.200-207 
